\author{
Article History \\ Received: 04-04-2020 \\ Revised: 27-06-2020 \\ Accepted: 16-07-2020 \\ Published: 29-09-2020
}

Copyright (C) 2020 Faculty of Veterinary Medicine, University of Maiduguri

All rights reserved

\title{
Facial and Body Morphometric Indices of the Arboreal African Pangolin (Manis tricuspis): Anthropometric Tools in Describing the Pangolin
}

\author{
${ }^{1 *}$ Igado, O. O., ${ }^{2}$ Adekanmbi, A. J., ${ }^{3}$ Adebayo, M. D., ${ }^{1}$ Sulaimon, O. T. and ${ }^{1}$ Osundina, O. A
}

${ }^{1}$ Department of Veterinary Anatomy, Faculty of Veterinary Medicine, University of Ibadan, Nigeria.
${ }^{2}$ Department of Anatomy, Faculty of Basic Medical Sciences, College of Medicine, University of Ibadan, Nigeria.
${ }^{3}$ Federal College of Animal Health and Production Technology, Ibadan, Nigeria

*Author for Correspondence: oo.igado@mail1.ui.edu.ng

\begin{abstract}
Body and craniofacial measurements are essential tools in identifying species and characterising their external traits. Body surface measurements were obtained from six African pangolins (Manis tricuspis) - 3 males and 3 females. Facial and body measurements obtained from the pangolins revealed that the females had higher averages for body weight, body length and girth. The dimensions of the head showed that the males had a wider zygoma. Also, the manus and arm (humerus) in the females were longer $(27.52 \pm 3.80 \mathrm{~mm}$ and $59.69 \pm 3.54 \mathrm{~mm}$ respectively) than in the males $(26.95 \pm 3.35 \mathrm{~mm}$ and $50.68 \pm 10.22$ $\mathrm{mm}$ respectively), while the lengths of the arm and the leg (all its components) were longer in the males. Data obtained from this study may provide basic information in assessing and comparing other species of the pangolin, and find application in archaeological, forensic and comparative anatomy of wildlife.
\end{abstract}

Keywords: Anthropometrics; African pangolin; Body indices; Craniofacial measurements

\section{INTRODUCTION}

The African pangolin (Manis tricuspis), also known as the white bellied pangolin or three cusped pangolin, is one of the eight extant species of pangolins native to West Africa and some parts of Central Africa (Waterman et al., 2014). The pangolins are rare unique modern mammals that belong to the order Pholidota. The nomenclature, pangolin, is derived from the Malay word, pengguling, which translated means "something that rolls up". This 'rolling up occurs when confronted by predators. In this event, the pangolins roll up into a ball, presenting just the scaly impenetrable parts to the predators. They are nocturnal, insectivorous animals, earning them the name "scaly anteaters" (Wang et al., 2016). They are toothless, possess no external ears (although they reputedly have good hearing), have a well-developed sense of hearing and poor eyesight. They also possess a highly muscular tongue which extends to the abdominal cavity (Adeniyi, 2010). They are the only mammals with their head, trunk, tail, upper and lower extremities completely covered in hard keratinous overlapping scales, except for a small part of their ventral skin which is scale free (Kawashima et al., 2015). The scales and skin make up about $20 \%$ to $25 \%$ of the body weight (Adeniyi, 2010; Wang et al., 2016). Pangolins are very high on the list of endangered animals, as they are hunted for several reasons in different climes, one prominent reason being for traditional medicine. Their body parts have been reputed to be useful for the treatment of rheumatism, convulsions, financial rituals (Boakye et al., 2015).

Body and cranial morphometrics are essential anthropometric tools that have been reported to assist in describing the basic conformation of different species, as well as determining the presence of deformations, and ultimately finding ways to manage such anomalous deformations (Onar and Günes, 2003). Phenotypic characterisation involves describing external traits including biometric measurements of each animal's body structure (De Melo et al., 2018). The use of body measurements has been employed to characterise and differentiate number of animal species, like Ugandan East African goats (Semakula et al., 2010), the Murrah crossbred buffalo (De Melo et al., 2018) and the Arapaima gigas fish (Luxinger et al., 2018).

Although several studies have explored different aspects of the pangolin anatomy (tongue and dentition (Adeniyi, 2010); nervous system (Imam et al., 2017, 2019); retinal and visual pathway (Adekanmbi et al., 2016; Adekanmbi and Akinola, 2017); scales (Wang et al., 2016), to mention a few, electronic search as at the time of this write-up did not reveal any documentation on the body indices in the arboreal African pangolin, as an anthropometric tool. Obtaining anthropometric data for descriptive purposes will aid in better understanding the morphological relationships that may exist among members of their phylogenetic relatives in the clade 
Ferae. In addition, data obtained will also help in the future unification of results between the morphological and molecular phylogenetic findings of the current work and future data to be obtained in these other species. As the field of archaeology is ever developing, data obtained from this study will also help in archaeological, forensic and comparative surface anatomy research of the pangolin family and related wildlife.

\section{MATERIALS AND METHODS}

Animals were obtained from surrounding forests in Akinyele Local Government (Ijaiye and Elekuru villages, $7.5309^{\circ} \mathrm{N}$, $3.9110^{\circ} \mathrm{E}$ ) in Ibadan, with the help of local hunters. They were picked during the day when they were least active (and could be handled with the least restraint). The Guide for the Care and Use of Laboratory Animals, NIH, USA (2011) was followed in handling the pangolins. Six adult pangolins were used for this study, 3 males and 3 females. Due to the fact that the pangolins are an endangered species, a larger number could not be used for this study. Animals were estimated to be adults based on weight, according to previously described methods (Adekanmbi and Akinola, 2017). Body weight was obtained with the aid of a standard digital kitchen scale (Camry ${ }^{\circledR}$, Model - EK5350, specificity $1 \mathrm{~g}$, China). This is the first in a series of studies on the anatomy of this species. Since other organs will be utilized in subsequent studies, the animals were euthanised with an overdose of xylazine 6 $\mathrm{mg} / \mathrm{kg}$ with ketamine $\mathrm{HCl} 150 \mathrm{mg} / \mathrm{kg}$ intramuscular injection (adapted from Catania et al., 2000). Linear measurements were obtained with the aid of a digital vernier caliper and tape measure, and recorded in millimetres, while all specimens were photographed with a digital camera (Sony ${ }^{\circledR}$ Cyber-shot digital still camera - DSC-HX400/HX400V). For all measurements that could be obtained bilaterally, the right side was recorded. This was maintained to avoid possible duplication of bilateral data. Measurements for craniofacial parameters were adapted from Igado et al. (2012) and Igado (2014), while length of body and other measurements on the long bones were adapted from Adetona and Shokunbi (2019). Since the full length of some of the long bones (e.g. humerus, femur and so on) cannot be accessed by palpation, the accessible points where they articulate with the adjoining bone(s) is taken as the limit of that bone, as adapted from Adetona and Shokunbi (2019) in humans.

Some of the parameters and their landmarks are shown in Figures $1-3$

1. Philtrum Height: Measured from the most dorsal and rostral aspect of the muzzle, to the lowest aspect of the philtrum.

2. Rima Oris width: This was determined using a thread, as the distance between the lateral commissures of the closed lips. The linear measurement was then determined using digital vernier caliper.

3. Widths of head, rostral, middle and caudal: This was the maximum width of the head, measured as the distance (i) between the right lateral and the left lateral sides of the snout cauda to the external nare across nasal bone, (ii) across the zygomatic bones and (iii) at the caudal portion of the frontal bone, across the ramus of mandible (cauda).

4. Palpebral Fissure width: Distance between the medial and lateral commissures of the eye.

5. Pinna Height: Since pinnae are absent in pangolins, what was described as "pinna" in this study, for ease of nomenclature, is the fold of skin that partially covers the auditory opening. This was measured from the base of the skin fold to its tip.

6. Pinna Width: This was measured as the wide distance between the lateral edges of the "pinna".

7. Height of the External Nares: Maximum vertical distance between the dorsal and ventral borders of the nares.

8. Width of the External Nares: Maximum horizontal distance between the lateral and medial borders of the nares.

9. Length of the Body: Measured from the philtrum to the tip of the tail.

10. Girth Size: Measured around the widest aspect of the abdominal region

11. Length of Humerus (arm): Measurement at the highest point from the scapulohumeral (shoulder) joint to the olecranium

12. Length of the Ulna (and radius) (forearm): measured from the olecranon to the proximal head of carpus.

13. Length of Carpus, Metacarpal and Phalanx (manus): Measured from the radioulna-carpal joint to the end of the third phalanx.

14. Length of Femur (thigh): Measured from the hip joint to the femoro-tibial (stifle) joint

15. Length of Tibia and Fibula (leg): Measured from stifle to the tarsocrural joint

16. Length of Tarsal, Metatarsal and Phalanx (pes): Measured from tarsocrural joint to the tip of the middle third digit.

\section{Ethical Approval}

Ethical approval for this study was obtained from the Animal Care and Use Research Ethics Committee (ACUREC), University of Ibadan, Nigeria, ethical code number UIACUREC/17/0023.

\section{Data Analysis}

All data were summarized into mean and presented in a tabular form.

\section{RESULTS}

Generally, the females were observed to have larger scales, with some of them chipped off. Three parameters were higher in males (rima oris width, cranial width at zygoma and the length of radius and ulna), while four parameters were higher in the females (width of the head at the snout, width of the 
external nares, length of body and the girth) (Table 1). The body weight was observed to be higher in the females (Table $1)$.
Linear measurements obtained for the hind limbs were consistently higher in the males, while the values for the forelimbs were inconsistent - the manus and arm were longer in the females while the forearms were longer in the males as shown on Table 1.

Table 1: Morphometric Measurements in the African pangolin (Manis tricuspis)

\begin{tabular}{llll}
\hline Parameters (unit) & $\begin{array}{l}\text { Male } \\
\text { Mean }(\mathbf{n = 3})\end{array}$ & $\begin{array}{l}\text { Female } \\
\text { Mean }(\mathbf{n = 3})\end{array}$ & $\begin{array}{l}\text { Total } \\
\text { Mean }(\mathbf{n = 6})\end{array}$ \\
\hline Body weight $(\mathrm{kg})$ & 1.62 & 1.89 & 1.76 \\
Philtrum height (mm) & 11.46 & 8.58 & 10.02 \\
Rima oris width (mm) & 43.13 & 39.19 & 41.16 \\
Width of head at the snout (mm) & 44.65 & 51.14 & 47.90 \\
Width of head across the zygoma (mm) & 85.57 & 76.41 & 80.90 \\
Width of head (caudal aspect of the frontal bone) (mm) & 121.5 & 129.5 & 125.5 \\
Palpebral fissure width (mm) & 11.55 & 11.19 & 11.37 \\
"Pinna" height (mm) & 26.46 & 27.51 & 26.98 \\
"Pinna" width (mm) & 9.13 & 7.24 & 8.18 \\
Height of external nares (mm) & 9.77 & 9.18 & 9.47 \\
Width of external nares (mm) & 1.86 & 2.05 & 1.96 \\
Length of the body (mm) & 43.98 & 52.75 & 48.36 \\
Girth (mm) & 25.18 & 26.18 & 25.68 \\
Length of arm (mm) & 50.68 & 59.69 & 55.18 \\
Length of forearm (mm) & 52.11 & 44.55 & 48.33 \\
Length of manus (mm) & 26.95 & 27.52 & 27.23 \\
Length of thigh (mm) & 53.49 & 48.86 & 51.17 \\
Length of leg (mm) & 79.17 & 65.42 & 72.29 \\
Length of pes (mm) & 30.55 & 25.85 & 28.20 \\
\hline
\end{tabular}

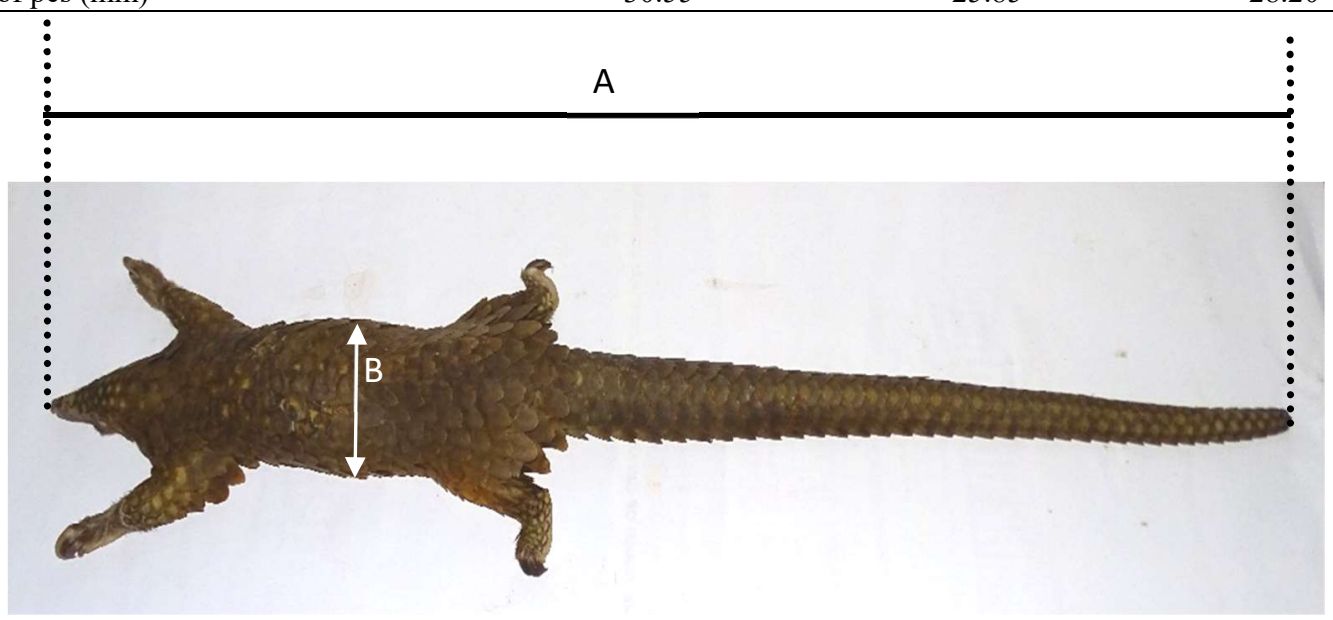

Figure 1: Dorsal view of the pangolin (Manis tricuspis), showing the length of the whole body (A) and the girth (B).

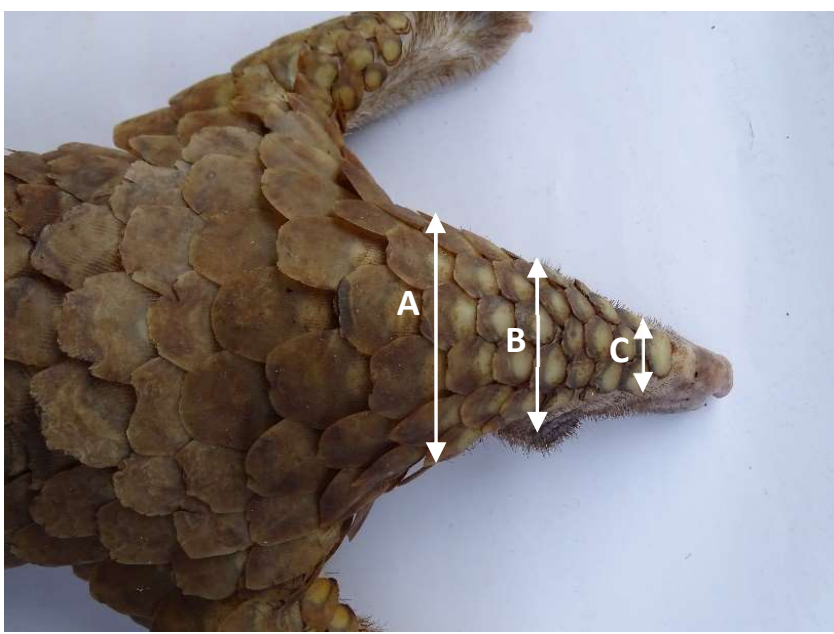

Figure 2: Dorsal view of the head of the pangolin (Manis tricuspis), showing the widths of the head at the caudal aspect (A), the zygoma (B) and the snout (C). 


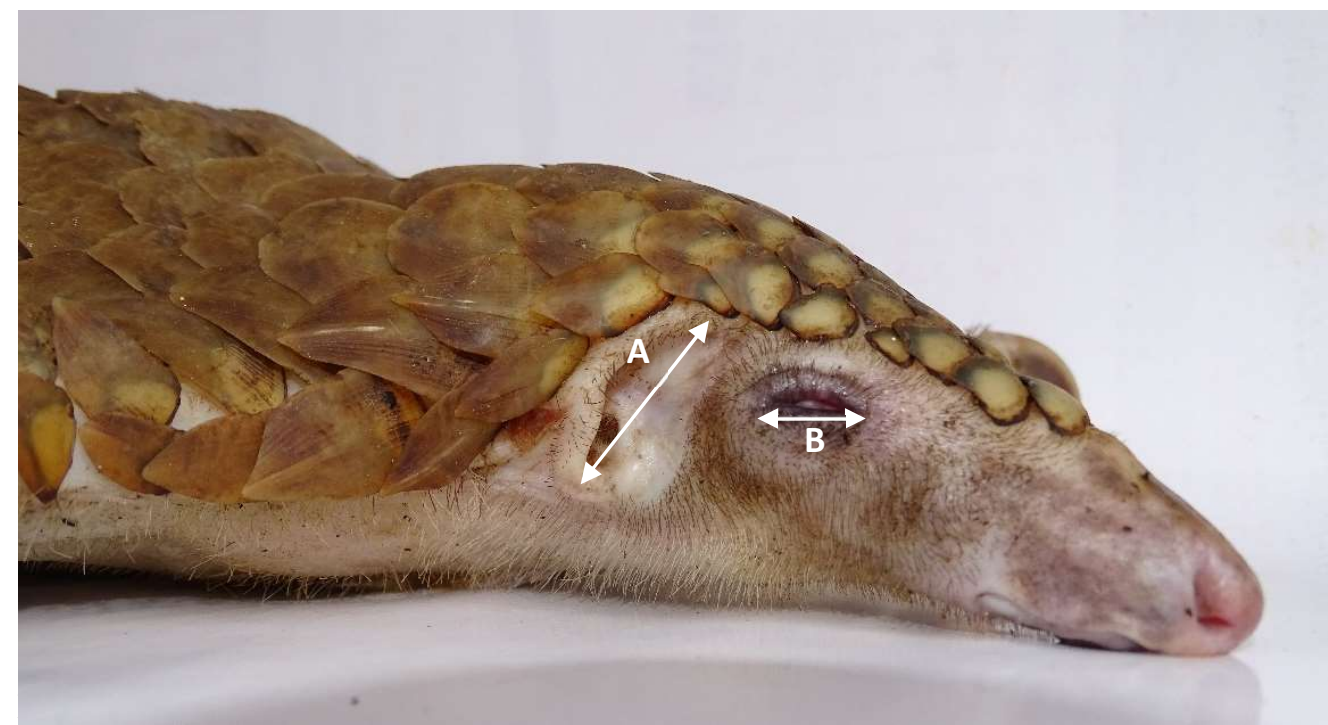

of the skin fold covering the auditory opening (A) and the palpebral fissure (B).

\section{DISCUSSION}

Phenotypic or morphometric characterisation of each animal species establishes its association between the conformation and function. These body biometric traits/characteristics may also contribute to the selection process of identifying morphological superior animals in cases of breeding selection (De Melo et al., 2018).

Although, measurements from the left and right sides for all bilateral parameters were taken, only the right was recorded, as slight negligible differences have been found to occur when these measurements are taken manually, even in other animals (Igado et al., 2012).

According to Campbell (1990), males are reported to have heavier body weights. Although, this statement has been confirmed in some other animals, like the Nigerian local dog (Igado, 2011), the fruit bat (Igado et al., 2012), it is contradictory to what was obtained in this study, where the females recorded heavier body weights, wider girths and longer bodies. Some other studies with similar reports to the current one include the Sahel goat (Olopade et al., 2007) and the Japanese quail (Igado and Aina, 2010). These differences may be incidental or due to the relatively random sampling or because the females used were probably dams, which could have resulted in the increased weight. This theory is supported by the fact that some of the female pangolins had some scales already chipped off, attesting to the fact that they were probably more advanced in age.

In spite of the larger weight in the females, the rima oris and the palpebral fissure widths were wider. The wider rima oris in the males may imply that they are the more voracious eaters. The heights of the philtrum and the external nares being higher in the males may be taken to indicate that the males possess a keener sense of smell as is postulated in some previous studies in the pig (Olopade et al., 2011) and the dog (Igado, 2014). However, in this current study, out of 7 parameters recorded relating to the nares, eyes and ears, four were higher in the males. This however could be used to imply that the females can also hunt and protect the group (especially when they are nursing mothers).
The dimensions of the pinnae may indicate that a particular gender of a species has a keener sense of hearing (Igado, 2014). Although the pangolins have no pinna, the fold partially covering the auditory opening may possibly perform some of the functions of the pinna. Results showed that the females had slightly higher values for the heights of this fold, while the males had higher values for the widths. These values may indicate that both genders are involved in the role of using the sense of hearing to enhance survival by watching out for predators as these animals are reported to have a keen sense of hearing (Adeniyi, 2010). The females recorded higher values for width of the head at the snout and caudal aspect of the frontal bone, while the males showed statistically significantly higher values for the width of the head at the zygoma. The zygomatic bones are the bones of the eye socket (Dyce et al., 2002), and these values may imply that the eyeballs of the males are bigger, probably inferring a wider range of sight.

Evaluating the surface osteometric values, the longer manus in the females could be an adaptation to enable greater ease in handling the young (since the females/dams are primarily responsible for the care of the young), while the longer arm may give them a longer reach. The femur is the longest bone in the mammalian body (Dyce et al., 2002) and is usually the bone used to estimate the height of the subject, in anthropology and archaeology or forensics. Following this theory, it can be inferred that the males captured in this study, having longer femurs, were probably still younger than the females, and may be classified as younger adults. A male captured at full potential may show higher values for the body length. Age-related studies in this respect may shed further light on the varying habits as related to the body indices in this unique animal.

Pangolins are high on the list of endangered animals (Shepherd et al., 2017), thereby putting a restriction on their handling and the number that can be accessed in the wild for experimental purposes. Data obtained from this study will serve as a baseline for morphometric indices and phylogenetic relatives in the clade Ferae and also help in the 
future unification of results between the morphological and molecular phylogenetic findings of the current work and future data to be obtained in other species of pangolins.

\section{Conclusion}

This study details the body and facial morphometrics of the pangolin, and will consequently form a basis for comparison to other members that are genetically related by classification or clade. Data obtained from this study will serve as a baseline for morphometric indices and phylogenetic relatives in the clade Ferae. In addition, it will help in the future unification of morphological and molecular phylogenetic findings to be obtained in the Manis tricuspis and other species of pangolins.

\section{Conflict of Interest}

The authors declare that they do not have any conflict of interest.

\section{Author's Contribution}

OOI and AAJ - research conceptualisation, data analysis, manuscript draft and editing; AMD, SOT and OOA obtaining animals, data collection and analysis.

\section{REFERENCES}

Adekanmbi, A.J., Adekanmbi, A.A. and Akinola, O.B. (2016). Short Wavelength Cone Opsin Is Not Expressed in the Retina of Arboreal African Pangolin (Manis tricuspis). Scientifica, 2016, 5 pages.

Adekanmbi, A.J. and Akinola, O.B. (2017) Eye Morphometrics and Retinal Organization in the Arboreal African Pangolin Supports Nocturnality. Arch. Bas Appl Med., 56 pages.

Adeniyi, P.A.O. (2010). Morphometric analysis of tongue and dentition in hedgehogs and pangolins. Eur. J. Anat., 14 (3): 149-152.

Adetona, M.O., and Shokunbi, M.T. (2019). Quantitative anthropometric and dermatoglyphic variation of the major ethnic populations in Nigeria. J. Exp Cl. Anat., 18:55-62

Boakye, M.K., Pietersen, D.W., Kotzé, A., Dalton, D-L., Jansen, R. (2015). Knowledge and Uses of African Pangolins as a Source of Traditional Medicine in Ghana. PLoS ONE 10(1): e0117199.

Catania, K.C., Collins, C.E. and Kaas, J.H. (2000) Organization of sensory cortex in the East African hedgehog (Atelerix albiventris). J. Comp. Neurol., 421 (2): 256-274.

Dyce K.M., Sack W.O., and Wensing C.J.G. (2002). Textbook of Veterinary Anatomy. 3rd edition, Saunders.

Guide for the Care and Use of Laboratory Animals, 8th edition. National Research Council (US) Committee for the Update of the Guide for the Care and Use of Laboratory Animals. Washington (DC): National Academies Press (US); 2011. ISBN13: 978-0-309-15400-0ISBN-10: 0-309-15400-6. https://www.ncbi.nlm.nih.gov/books/NBK54050/

Igado, O.O. (2014). A Study of the Craniofacial Morphometry of the Nigerian Local Dog. J. Sc. Res.,
$131-4$.

Igado, O.O. (2011). Gross morphometric study of the eyeball and tongue of the Nigerian local dog. IJAE. 116 (1): 104-110.

Igado, O.O. and Aina, O.O. (2010) Some aspects of the neurometrics and oculometrics of the japanese quail (Coturnix coturnix japonica) in Nigeria. J. Morph. Sc., 27 (3-4): 133-135.

Igado, O.O., Omobowale, T.O., Ajadi, R.A. and Nottidge, H.O. (2012). Craniofacial morphometrics and macroneurometrics of the fruit bat (Eidolon Helvum). Eur. J. Anat., 16 (3): 172-176.

Imam, A., Ajao, M.S., Bhagwandin, A., Ihunwo, A.O. and Manger, P.R. (2017). The brain of the tree pangolin (Manis tricuspis). I. General appearance of the central nervous system. J. Comp. Neurol., 525 (11): 25712582.

Imam, A., Bhagwandin, A., Ajao, M.S. and Manger, P.R. (2019). The brain of the tree pangolin (Manis tricuspis). V . The diencephalon and hypothalamus. J. Comp. Neurol., 527(15): 2413-2439.

Kawashima, T., Thorington, R.W., Bohaska, P.W., Chen, Y.J. and Sato, F. (2015) Anatomy of Shoulder Girdle Muscle Modifications and Walking Adaptation in the Scaly Chinese Pangolin (Manis Pentadactyla Pentadactyla: Pholidota) Compared with the Partially Osteoderm-Clad Armadillos (Dasypodidae). Anat. Rec., 298 (7): 1217-1236.

Luxinger, A.O., Cavali, J., Porto, M.O., Sales-Neto, H.M., Lago, A.A. and Freitas, R.T.F. (2018). Morphometric measurements applied in the evaluation of Arapaima gigas body components. Aquaculture. 489: 80-84.

De Melo, B.A., Nascimento, I. de M., dos Santos, L.T.A., de Lima, L.G., de Araújo, F.C.T., Rios, R.R.S., Couto, A. de G. and Fraga, A.B. (2018) Body morphometric measurements in murrah crossbred buffaloes (Bubalus bubalis). J. Appl. An. Res., 46 (1): 1307-1312.

Olopade, J.O., Igado, O.O., Nwafor, C.I., Alamu, A.O. and Onwuka, S.K. (2011). Some aspects of the craniofacial indices and macro neurometrics of the Nigerian local pig (Sus scrofa). IJAE, 116 (1): 38-44.

Olopade, J.O., Kwari, H.D., Shawulu, J.C., Ofua, M. and Onwuka, S.K. (2007) Some aspects of the neurometrics of the Sahel goat in Nigeria. Eur. J. Anat., 11 (2): 101-104.

Onar, V. and Günes, H. (2003). On the variability of skull shape in German shepherd (Alsatian) puppies. The Anatomical Record Part A: Discoveries in Molecular, Cellular, and Evolutionary Biology. 272A (1): 460466.

Semakula, J., Mutetikka, D., Kugonza, D.R. and Mpairwe, D. (2010) Variability in Body Morphometric Measurements and Their Application in Predicting Live Body Weight of Mubende and Small East African Goat Breeds in Uganda. Middle-East J. Sci. Res., 5 (2): 98-105.

Shepherd, C., Connelly, E., Hywood, L. and Cassey, P. (2017) Taking a stand against illegal wildlife trade: the Zimbabwean approach to pangolin conservation. Oryx. 51 (2): 280-285.

Wang, B., Yang, W., Sherman, V.R. and Meyers, M.A. 
(2016) Pangolin armor: Overlapping, structure, and mechanical properties of the keratinous scales. Acta Biomaterialia., 4160-74.
Waterman, C., Pietersen, D.W., Soewu, D., Hywood, L. and Rankin, P. (2014) Phataginus tricuspis. The IUCN Red List of Threatened Species 2014. 